\title{
LIBERAÇÃO CONTROLADA DE INSULINA ATRAVÉS DE HIDROGÉIS DE ÁCIDO ACRÍLICO / TRIMETILOLPROPANO TRIACRILATO
}

\author{
L. G. AGUIAR', V. C. RAYMUNDI², E. F. SOUZA', A. C. SATO ${ }^{3}$, R. GIUDICI ${ }^{1}$ \\ ${ }^{1}$ Escola Politécnica da Universidade de São Paulo, Dep. Engenharia Química \\ ${ }^{2}$ Faculdades Oswaldo Cruz \\ ${ }^{3}$ Instituto Butantan - Laboratório de Bioquímica e Biofísica \\ E-mail para contato: rgiudici@usp.br
}

\begin{abstract}
RESUMO - Hidrogéis de ácido acrílico reticulados com trimetilolpropano triacrilato (TMPTA) foram produzidos através de polimerização em solução. Estes hidrogéis foram carregados com solução de insulina e os índices de intumescimento foram registrados. Ensaios de liberação controlada de insulina foram conduzidos em meios ácido e básico a fim de se avaliar a taxa de transferência desta proteína através do hidrogel. Os perfis de intumescimento e de concentração de insulina liberada mostraram-se inversamente proporcionais aos graus de reticulação, como esperado. Adicionalmente, uma descrição matemática do sistema foi feita com base em balanços diferenciais de massa para a insulina. Obteve-se boa concordância entre os resultados experimentais e as respectivas previsões do modelo matemático. Os valores ajustados de difusividade da insulina através dos hidrogéis mostraram-se coerentes em relação à acidez do meio e ao grau de reticulação de cada hidrogel. Os valores experimentais e ajustados dos coeficientes de partição da insulina entre o gel e a solução mostraram-se baixos para o meio básico, indicando boa afinidade da insulina por este meio em comparação com o meio ácido.
\end{abstract}

\section{INTRODUÇÃO}

A insulina desempenha um papel importante no tratamento do diabetes mellitus, uma vez que pacientes com este tipo de doença precisam administrar insulina exógena devido à total ou parcial destruição de células pancreáticas produtoras desse hormônio (American Diabetes Association, 2012). O tratamento do diabetes se dá através de injeções diárias representando uma inconveniência aos pacientes diabéticos. Porém, a administração de insulina por rota oral depara-se com o problema de sua degradação quando em contato com o suco gástrico. Esforços direcionados à modificação química da insulina e co-administração de adjuvantes têm sido feitos no sentido de sobrepor as barreiras de administração oral de insulina (Sajeesh e Sharma, 2006).

Com os contínuos avanços na ciência dos polímeros, campos como o da engenharia química, farmácia e biomedicina estão sendo integrados para desenvolver materiais poliméricos para aplicações específicas. Dentre as diferentes aplicações, destaca-se a liberação controlada de medicamentos através do uso de hidrogéis (Langer, 1998; Peppas, 
1986; Park, 1997; Peppas, 1997; Rasool, 2010). Este material incha em meio aquoso e é capaz de responder a estímulos. O presente trabalho objetiva verificar a adequabilidade do hidrogel feito com ácido acrílico e trimetilolpropano triacrilato (TMPTA) para a liberação controlada de insulina. Este copolímero tem característica superabsorvente, sendo capaz de captar grandes quantidades de solução aquosa. Sua produção se dá através da adição de pequenas quantidades de TMPTA (cerca de $0,1 \%$ ), que atua como reticulante na polimerização, representando uma vantagem econômica.

Neste trabalho foram estudados os perfis de intumescimento de hidrogéis de ácido acrílico com diferentes dosagens de TMPTA e a taxa de liberação de insulina em meios com diferentes pHs. Um modelo matemático foi proposto para representar a cinética de liberação de insulina do gel para o meio.

\section{MATERIAIS E MÉTODOS}

\subsection{Parte Experimental}

Hidrogéis de (ácido acrílico)-co-TMPTA com diferentes formulações foram produzidos através de polimerização por radicais livres em solução aquosa. As reações foram realizadas a $70^{\circ} \mathrm{C}$ em recipientes de vidro contendo $100 \mathrm{~mL}$ de mistura reacional. As polimerizações foram iniciadas através da decomposição térmica do iniciador persulfato de sódio. Quantidades conhecidas de ácido acrílico, TMPTA e água deionizada foram misturadas e aquecidas até $70^{\circ} \mathrm{C}$ e então, o iniciador foi adicionado, dando início à polimerização. Todas as reações deste estudo foram realizadas com uma razão volumétrica ácido acrílico / água de 0,3 e uma razão molar iniciador / ácido acrílico de $2 \times 10^{-4}$. A Tabela 1 fornece as frações molares de reticulante (TMPTA) na mistura de monômeros (ácido acrílico + TMPTA) para cada hidrogel produzido $\left(\mathrm{Y}_{\mathrm{C}}\right)$.

A insulina foi incorporada ao hidrogel através do método de carregamento por difusão (Sajeesh e Sharma, 2006). Cada hidrogel foi mantido em contato com soluções ácidas (preparada com $\mathrm{HCl}$ e com $\mathrm{pH}$ em torno de 1,3) e básicas (preparada com $\mathrm{NaOH}$ e com $\mathrm{pH}$ em torno de 11,0) de insulina a $4 \mathrm{UI} / \mathrm{mL}$. Dois ensaios de liberação controlada foram conduzidos em paralelo para cada hidrogel. Após o procedimento de intumescimento, pesouse de 2,5 a 3 g do hidrogel intumescido em cada ensaio, os quais foram adicionados a um recipiente contendo de 25 a $30 \mathrm{~mL}$ de solução aquosa, dando início ao ensaio de liberação controlada de insulina. Esta solução aquosa consistiu de solução de $\mathrm{HCl}$ para os hidrogéis intumescidos em meio ácido e solução de $\mathrm{NaOH}$ para os hidrogéis intumescidos em meio básico (pHs ajustados para os valores finais das respectivas soluções de carregamento). A temperatura utilizada nos estudos de liberação controlada foi de $36 \pm 2^{\circ} \mathrm{C}$. Amostras foram coletadas em triplicata em tempos pré-estabelecidos e conduzidas à análise de proteínas. Os ensaios foram nomeados conforme mostrado na Tabela 1. A determinação da concentração de proteínas foi realizada conforme o método descrito por Lowry et al. (1951). A absorbância foi medida a $36 \pm 2{ }^{\circ} \mathrm{C}$ por um espectrofotômetro QUIMIS Spectro $22 \mathrm{RS}$ no comprimento de onda de $750 \mathrm{~nm}$. 
Tabela 1 - Nomenclatura dos ensaios de liberação controlada

\begin{tabular}{cccc}
\hline Hidrogel & $\mathrm{Y}_{\mathrm{C}}(\%)$ & $\begin{array}{c}\text { Ensaios em } \\
\text { solução ácida }\end{array}$ & $\begin{array}{c}\text { Ensaios em } \\
\text { solução básica }\end{array}$ \\
\hline HG1 & 0,01 & A1 & B1 \\
HG2 & 0,15 & A2 & B2 \\
HG3 & 0,30 & A3 & B3 \\
\hline
\end{tabular}

\subsection{Modelagem Matemática}

Um estudo computacional foi realizado para representar matematicamente o sistema de liberação de insulina através do hidrogel. A abordagem utilizada está baseada no balanço diferencial de massa aplicado para coordenadas esféricas, supondo que: cada partícula de hidrogel possui o formato aproximado de uma esfera; a densidade do sistema e as difusividades dos componentes são constantes ao longo do processo; o transporte convectivo é desprezível dentro do hidrogel; não há reações químicas ocorrendo no sistema; gradiente de concentração é formado somente na direção radial (r) do hidrogel e o meio fora do hidrogel é homogêneo. Com estas hipóteses, o balanço diferencial de massa pode ser simplificado conforme descrito a seguir.

\section{Dentro do hidrogel (Fase I)}

$$
\frac{\partial C_{A}^{I}}{\partial t}=D_{A}\left[\frac{\partial^{2} C_{A}^{I}}{\partial r^{2}}+\frac{1}{r} \frac{\partial C_{A}^{I}}{\partial r}\right]
$$

As condições de contorno para esta equação são:

Para $\mathrm{t}=0, C_{A}^{I}=C_{A, \text { inicial }}^{I} ;$ para $\mathrm{r}=0,\left.\frac{\partial C_{A}^{I}}{\partial r}\right|_{r=0}=0 ;$ para $\mathrm{r}=\mathrm{R}$,

$$
-\left.D_{A} \frac{\partial C_{A}^{I}}{\partial r}\right|_{r=R}=k_{c}\left(\frac{\left.C_{A}^{I}\right|_{r=R}}{K_{P}}-C_{A}^{I I}\right)
$$

sendo que: $K_{P}=\frac{\left.C_{A}^{I}\right|_{r=R}}{C_{A, e q}^{I I}}($ Coeficiente de partição da insulina entre as fases I e II); $C_{A, e q}^{I I}$ : Concentração de insulina na fase II em equilíbrio com $\left.C_{A}^{I}\right|_{r=R}$.

A equação (1) foi resolvida pelo método das linhas, conforme mostrado nas equações (2)-(6). Aplicando-se o método das diferenças finitas à fase I:

$$
\left.\frac{\partial C_{A}^{I}}{\partial r}\right|_{j} \cong \frac{C_{A, j+1}^{I}-C_{A, j-1}^{I}}{2 \Delta r}
$$




$$
\left.\frac{\partial^{2} C_{A}^{I}}{\partial r^{2}}\right|_{j} \cong \frac{C_{A, j+1}^{I}-2 C_{A, j}^{I}+C_{A, j-1}^{I}}{(\Delta r)^{2}}
$$

$\operatorname{Para} 2 \leq \mathrm{j} \leq \mathrm{N}$

$$
\frac{d C_{A, j}^{I}}{d t}=D_{A}\left[\frac{C_{A, j+1}^{I}-2 C_{A, j}^{I}+C_{A, j-1}^{I}}{(\Delta r)^{2}}+\frac{C_{A, j+1}^{I}-C_{A, j-1}^{I}}{r_{j} \Delta r}\right]
$$

sendo que: $\Delta r=\frac{R}{N} ; r_{j}=(j-1) \Delta r$.

Usando-se as condições de contorno, obtém-se expressões para $C_{A, 1}^{I}$ e $C_{A, N+1}^{I}$ :

$$
\begin{aligned}
& \frac{d C_{A, 1}^{I}}{d t}=6 D_{A}\left[\frac{C_{A, 2}^{I}-C_{A, 1}^{I}}{(\Delta r)^{2}}\right] \\
& \frac{d C_{A, N+1}^{I}}{d t}=D_{A}\left[\frac{C_{A, N}^{I}-\frac{2 k_{C} \Delta r}{D_{A}}\left(\frac{C_{A, N+1}^{I}}{K_{P}}-C_{A}^{I I}\right)-2 C_{A, N+1}^{I}+C_{A, N}^{I}}{(\Delta r)^{2}}+\frac{C_{A, N}^{I}-\frac{2 k_{C} \Delta r}{D_{A}}\left(\frac{C_{A, N+1}^{I}}{K_{P}}-C_{A}^{I I}\right)-C_{A, N}^{I}}{r_{j} \Delta r}\right]
\end{aligned}
$$

$\underline{\text { Fora do hidrogel (Fase II) }}$

$$
\frac{d C_{A}^{I I}}{d t}=k_{C}\left(\frac{C_{A, N+1}^{I}}{K_{P}}-C_{A}^{I I}\right) a_{v} \frac{V^{I}}{V^{I I}}
$$

As equações diferenciais (4)-(7) foram integradas numericamente em MATLAB através do algoritmo ode45. O Valor de $\mathrm{N}$ foi aumentado até se obter previsões constantes. As simulações apresentadas foram feitas com $\mathrm{N}=10$.

\section{RESULTADOS E DISCUSSÕES}

O índice de intumescimento dos hidrogéis foi calculado através da equação (8).

$$
S w=\frac{W_{s w}-W_{d}}{W_{d}}
$$


sendo que $\mathrm{W}_{\mathrm{sw}}$ é a massa do hidrogel intumescido e $\mathrm{W}_{\mathrm{d}}$ é a massa do hidrogel seco. Os perfis de índice de intumescimento obtidos para as soluções ácida e básica de insulina estão ilustrados na Figura 1.
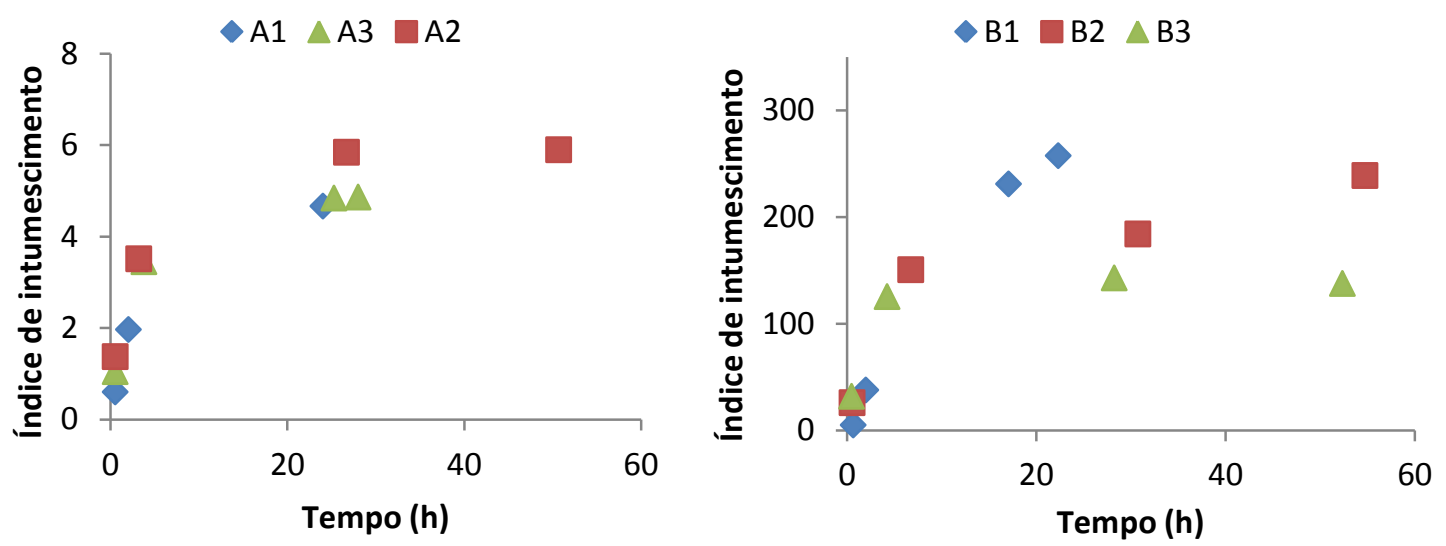

Figura 1 - Curvas de índice de intumescimento obtidas durante o carregamento de soluções ácida (esquerda) e básica (direita) de insulina.

A característica aniônica do hidrogel de (ácido acrílico)-TMPTA torna-se evidente quando os gráficos da Figura 1 são comparados. No meio ácido, os hidrogéis aumentaram suas massas menos de 8 vezes, enquanto que em meio básico, obtiveram-se massas finais entre 100 e 350 vezes a massa inicial. Observa-se que o índice de intumescimento é função do grau de reticulação. $O$ índice de intumescimento de equilíbrio diminui à medida que a densidade de ligações cruzadas aumenta (HG1 para HG3). Este comportamento era esperado, uma vez que, um aumento no grau de reticulação resulta em menor expansão dos segmentos de polímero. A Tabela 2 lista os números de partículas de hidrogel e os volumes inicial e final da fase hidrogel (Fase I) nos ensaios de liberação controlada.

Tabela 2 - Dados do hidrogel nos ensaios de liberação controlada.

\begin{tabular}{ccccccc}
\hline & A1 & B1 & A2 & B2 & A3 & B3 \\
\hline Número de partículas & 3 & 2 & 2 & 3 & 2 & 4 \\
Volume inicial (mL) & 3,0 & 3,0 & 1,5 & 3,0 & 2,4 & 2,8 \\
Volume final (mL) & 3,2 & 5,8 & 2,0 & 2,4 & 2,8 & 2,8 \\
Variação (\%) & 6,7 & 93,3 & 33,3 & $-20,0$ & 16,7 & 0,0 \\
\hline
\end{tabular}

Durante a validação do modelo, encontrou-se um conjunto de parâmetros que permitiu o bom ajuste do mesmo aos dados experimentais estudados. Nas simulações, foi considerado um valor médio de volume de hidrogel, que foi calculado com base nos valores inicial e final. Os valores de $\mathrm{R}$ e $\mathrm{a}_{\mathrm{v}}$ foram determinados com base neste volume médio, considerando-se que, em cada ensaio, as partículas de hidrogel consistiram de esferas de igual tamanho. A Figura 2 mostra os resultados de liberação controlada. 

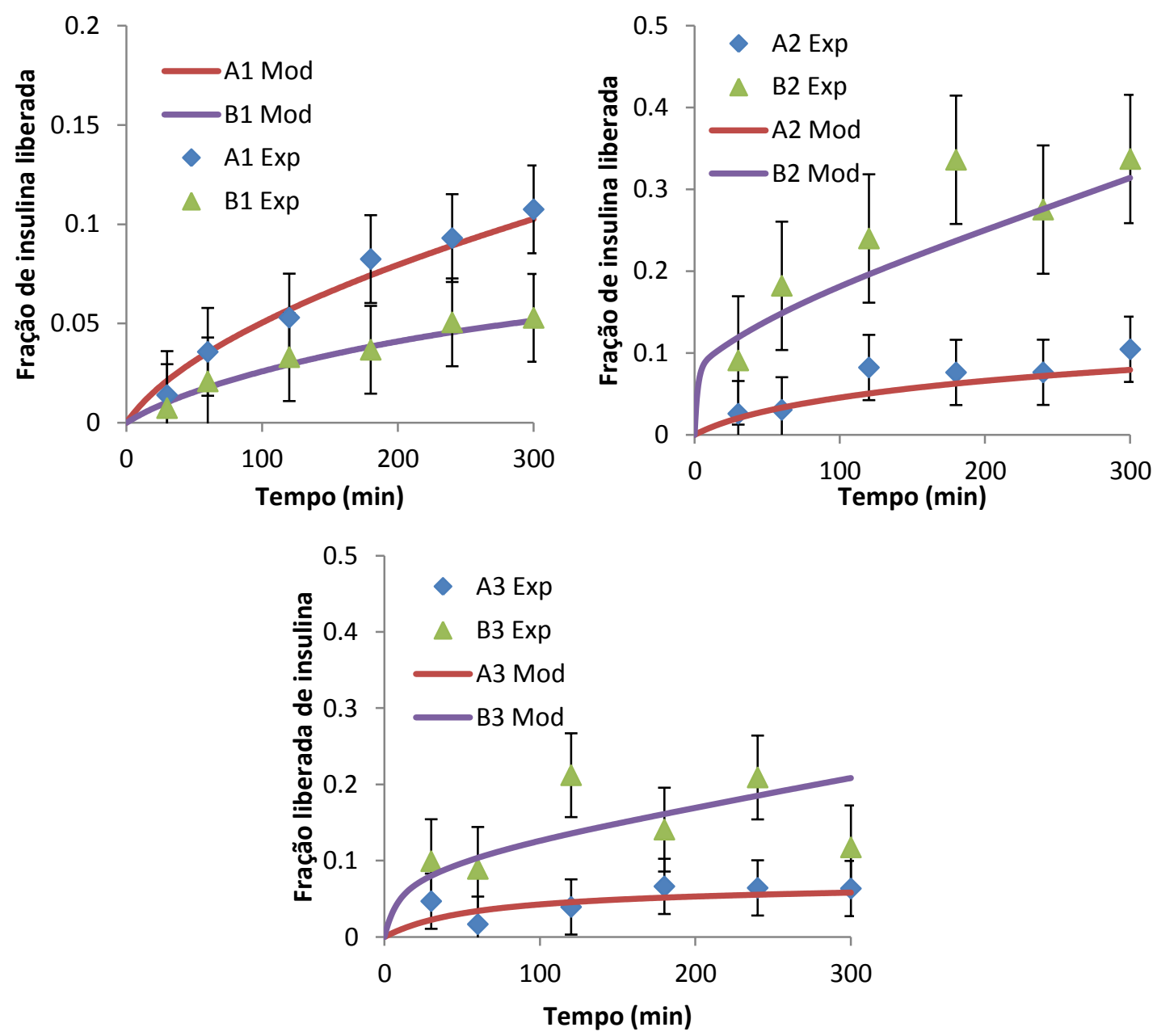

Figura 2 - Resultados de liberação controlada de insulina. EXP: Dados experimentais, MOD: Previsão do modelo.

Os perfis experimentais de liberação para os ensaios B2 e B3 situam-se acima dos perfis de A2 e A3 respectivamente. Por outro lado, o perfil de A1 mostra-se acima do perfil de B1. Estes diferentes resultados podem ser explicados pela competição de efeitos provocados pela variação da acidez do meio sobre a taxa de liberação. Em meio básico, o hidrogel intumesce mais do que em meio ácido. Isto causa um aumento no diâmetro de seus poros, aumentando-se assim a taxa de liberação. Porém, quanto mais intumescido estiver o hidrogel, maior será a distância a ser percorrida pela insulina até atingir a solução externa, resultando em maior resistência à transferência de massa.

Os parâmetros ajustados no modelo foram os seguintes: difusividade da insulina através do hidrogel $\left(\mathrm{D}_{\mathrm{A}}\right)$, coeficiente de transferência de massa da insulina na solução receptora $\left(\mathrm{k}_{\mathrm{c}}\right)$ e coeficiente de partição da insulina entre as fases I e II $\left(\mathrm{K}_{\mathrm{P}}\right)$. A Tabela 3 apresenta os valores ajustados para estes parâmetros. 
Tabela 3 - Parâmetros de simulação.

\begin{tabular}{ccccccc}
\hline & $\mathrm{A} 1$ & $\mathrm{~A} 2$ & $\mathrm{~A} 3$ & $\mathrm{~B} 1$ & $\mathrm{~B} 2$ & $\mathrm{~B} 3$ \\
\hline $\mathrm{K}_{\mathrm{P}} \exp *$ & 38,50 & 41,45 & 50,49 & 25,74 & 12,79 & 41,03 \\
$\mathrm{~K}_{\mathrm{P}}$ ajustado & 20,00 & 44,00 & 50,00 & 28,00 & 1,00 & 15,00 \\
$\mathrm{D}_{\mathrm{A}}\left(\mathrm{cm}^{2} / \mathrm{s}\right)$ & $1,0 \times 10^{-6}$ & $7,0 \times 10^{-7}$ & $6,0 \times 10^{-7}$ & $1,3 \times 10^{-6}$ & $9,0 \times 10^{-7}$ & $8,0 \times 10^{-7}$ \\
$\mathrm{k}_{\mathrm{c}}(\mathrm{cm} / \mathrm{s})$ & $1,0 \times 10^{-4}$ & $2,0 \times 10^{-4}$ & $3,0 \times 10^{-4}$ & $8,0 \times 10^{-5}$ & $2,0 \times 10^{-4}$ & $5,0 \times 10^{-4}$ \\
\hline \multicolumn{7}{c}{$* \mathrm{~K}_{\mathrm{P}}$ obtido experimentalmente. }
\end{tabular}

Os valores experimentais de $\mathrm{K}_{\mathrm{P}}$ foram calculados com base na última amostra coletada em cada ensaio de liberação controlada. Foram observados valores altos de $\mathrm{K}_{\mathrm{P}}$ para os experimentos conduzidos em meio ácido (43,48 em média) em comparação com o meio básico (26,52 em média). Estes valores sugerem que a insulina tem maior afinidade pelo meio básico em relação ao meio ácido. Entretanto, valores mais realistas de $\mathrm{K}_{\mathrm{p}}$ apresentar-se-iam numa faixa inferior aos valores mostrados na Tabela 3 , uma vez que o equilíbrio pode não ter sido atingido ao final de cada ensaio.

Foram obtidos valores mais baixos de $\mathrm{D}_{\mathrm{A}}$ para hidrogéis com maiores graus de reticulação e maiores para hidrogeis menos reticulados, conforme esperado. As oscilações no valor de $\mathrm{k}_{\mathrm{c}}$ podem estar associadas à variações de temperatura e de manuseio durante a coleta das amostras. Com o presente modelo foi feita uma simulação simplificada (sem levar em conta processos bioquímicos) para avaliar a administração oral de insulina a um paciente diabético que necessita de duas doses diárias de 20 UI. Nesta simulação foi constatado que cada dose administrada seria equivalente à ingestão de cerca de 70 partículas de $2 \mathrm{~mm}$ de diâmetro do hidrogel HG2, intumescidas com $100 \mathrm{UI} / \mathrm{mL}$. Esta equivalência leva em conta 2 $\mathrm{h}$ de residência no estômago (meio ácido) e uma perda de cerca de $18 \%$ da insulina carregada no hidrogel. Na simulação, foram consideradas $3 \mathrm{~h}$ de residência no duodeno (meio neutro / básico), onde se obtém um aproveitamento de $73 \%$ da insulina carregada no hidrogel, que corresponde às 20 UI necessárias.

\section{CONCLUSÃO}

O presente hidrogel mostrou altos índices de intumescimento em meio básico em comparação com o meio ácido, comprovando seu caráter aniônico. O carregamento de hidrogeis com soluções de insulina forneceu perfis que estão de acordo com a concentração de reticulante utilizado na produção de cada hidrogel, isto é, quanto maior for o grau de reticulação, menor será o índice de intumescimento de equilíbrio. Os hidrogéis mais reticulados (HG2 e HG3) geraram taxas de liberação superiores para o meio básico em relação ao meio ácido. Assim, a faixa de reticulação destes hidrogéis mostra-se interessante para a aplicação desejada. Foi obtida boa concordância entre os dados experimentais e o modelo desenvolvido. Os valores ajustados de difusividade de insulina no gel se apresentaram decrescentes com o aumento do grau de reticulação, conforme esperado. Os coeficientes de partição da insulina entre as fases I e II foram estimados experimentalmente e apresentaram valores médios de 43,48 para o meio ácido e 26,52 para o meio básico. Estes resultados indicam maior afinidade da insulina pelo meio básico. Este hidrogel é uma opção para entrega controlada de insulina via oral, uma vez que a perda de insulina em meio ácido é 
relativamente pequena. Porém, esforços devem ser direcionados a um melhor controle das variáveis deste estudo a fim de se adequar o presente sistema à sua aplicação final.

\section{NOMENCLATURA}

$\begin{array}{ll}\mathrm{a}_{\mathrm{v}} & \text { Área superficial do hidrogel por unidade de volume }\left(\mathrm{cm}^{-1}\right) \\ C_{A}^{j} & \text { Concentração de insulina na fase 'j' }\left(\mathrm{IU} / \mathrm{cm}^{3}\right) \\ \mathrm{D}_{\mathrm{A}} & \text { Difusividade da insulina dentro do gel intumescido }\left(\mathrm{cm}^{2} / \mathrm{s}\right) \\ \mathrm{k}_{\mathrm{c}} & \text { Coeficiente de transferência de massa de insulina na solução }(\mathrm{cm} / \mathrm{s}) \\ K_{P} & \text { Coeficiente de partição da insulina entre as fases I e II } \\ \mathrm{N} & \text { Número de pontos usados no método das linhas } \\ \mathrm{R} & \text { Raio do hidrogel }(\mathrm{cm}) \\ \mathrm{V}^{\mathrm{j}} & \text { Volume da fase ' 'j' }\left(\mathrm{cm}^{3}\right)\end{array}$

\section{REFERÊNCIAS}

AMERICAN DIABETES ASSOCIATION. Diagnosis and classification of Diabetes Mellitus. Diabetes Care, v. 35, n.1, p. 564-571, 2012.

ENDE, M. T.; PEPPAS, N. A. Transport of ionizable drugs and proteins in crosslinked poly(acrylic acid) and poly(acrylic acid-co-2-hydroxyethyl methacrylate) hydrogels. II. Diffusion and release studies. Journal of Controlled Release, v. 48, p. 47-56, 1997.

LANGER, R., Drug delivery and targeting, Nature, 392, 5, 1998.

LOWRY, O. H. et al. Protein measurement with the folin phenol reagent. Journal of Biological Chemistry, v.193, p. 265-275, 1951.

PARK, K., controlled release: Challenges and strategies, American chemical society, Washington D. C, 1997.

PEPPAS, N. A., Hydrogels in medicine, CRS Press, Boca Raton, FL, 1986.

PEPPAS, N. A., Hydrogels and drug delivery, Curr. Opin. Coll. Int. Sci. 2, 531-537, 1997.

RASOOL, N. et al. Synthesis and characterization of novel $\mathrm{pH}$-, ionic strength and temperature- sensitive hydrogel for insulin delivery. Polymer, v. 51, p. 1687-1693, 2010.

SAJEESH, S.; SHARMA, C. P. Cyclodextrin-insulin complex encapsulated polymethacrylic acid based nanoparticles for oral insulin delivery. International Journal of Pharmaceutics, v. 325, p. 147-154, 2006. 